\title{
Polymer/silicate Interaction in Nylon 6-Clay Hybrid Studied by Temperature Programmed Pyrolysis Techniques
}

\author{
Hiroaki Sato, ${ }^{1}$ Hajime Ohtani,,${ }^{2, \dagger}$ Ryo Harada,${ }^{3}$ Shin Tsuge, ${ }^{3}$ \\ Makoto KATO, ${ }^{4}$ and Arimitsu UsUKI ${ }^{4}$ \\ ${ }^{1}$ Research Institute for Environmental Management Technology, National Institute of Advanced \\ Industrial Science and Technology (AIST), 16-1 Onogawa, Tsukuba 305-8569, Japan \\ ${ }^{2}$ Department of Materials Science and Engineering, Graduate School of Engineering, \\ Nagoya Institute of Technology, Gokiso-cho, Showa-ku, Nagoya 466-8555, Japan \\ ${ }^{3}$ Department of Applied Chemistry, Graduate School of Engineering, Nagoya University, \\ Furo-cho, Chikusa-ku, Nagoya 464-8603, Japan \\ ${ }^{4}$ Toyota Central Research and Development Laboratories, Inc., Nagakute-cho, Aichi-gun 480-1192, Japan
}

(Received August 22, 2005; Accepted October 12, 2005; Published February 15, 2006)

\begin{abstract}
Nylon 6-clay hybrid (NCH) was characterized by temperature-programmed pyrolysis (TPPy) techniques such as TPPy-mass spectrometry and TPPy-gas chromatography mainly focusing on the interaction between nylon 6 molecule and the surface of silicate monolayers in the NCH samples, which leads to the superior properties of the hybrid nanomateirals. Pyrolysis profile of nylon 6 matrix in the NCH samples was gradually shifted to lower temperature region with increase in the clay content. The yields of main pyrolysis products such as $\varepsilon$-caprolactam from the NCH samples decreased with increase in the clay content, whereas those of the nitrile compounds significantly increased. These results suggested that the clay surface accelerate cis-elimination reaction of nylon 6 matrix in the $\mathrm{NCH}$ samples to form the nitrile compounds rather than intramolecular amide exchange to $\varepsilon$-caprolactam. Based on the changes in pyrolysis behaviors of nylon 6 matrix in the $\mathrm{NCH}$ samples, the interaction between positively charged $\mathrm{NH}$ proton of nylon 6 molecules and negatively charged clay surface was proposed which would stabilize the six-membered transition state during pyrolysis. [DOI 10.1295/polymj.38.171]

KEY WORDS Nylon 6-clay Hybrid / Polymer-silicate Interaction / Nanocomposite / Pyrolysis / Gas Chromatography / Mass Spectrometry /
\end{abstract}

In the past decade, much interest has been paid to polymer-layered silicate nanocomposite materials, because they frequently exhibit various unique properties which could not be manifested in the case of a constituent polymer alone. ${ }^{1-6}$ Nylon 6-clay hybrid $(\mathrm{NCH})$ is the herald of the polymer-layered silicate nanocomposite materials, in which each silicate monolayer with ca. $1 \mathrm{~nm}$ thick is homogeneously dispersed in nylon 6 matrix. ${ }^{7}$ Because $\mathrm{NCH}$ has various excellent properties over pure nylon 6 such as high strength, high modulus, high distortion temperature, and low gas permeability, it has been utilized as industrial materials such as automotive parts and package films. ${ }^{8-10}$

The interaction mechanisms between nylon 6 molecules and clay surface in $\mathrm{NCH}$ are of great interest to understand their unique properties. So far, the interaction between amino acid and clay mineral in intercalated compounds of montmorillonite with glycine as the model $\mathrm{NCH}$ was estimated using ${ }^{15} \mathrm{~N}$ cross polarization magic angle spinning (CP/MAS) nuclear magnetic resonance spectroscopy (NMR). ${ }^{9}$ In this study, it was suggested that the cationic terminal amino groups of nylon 6 molecules might interact strongly with negatively charged clay surface. The crystalline structures of nylon 6 molecules in $\mathrm{NCH}$, which have been often characterized by X-ray diffraction and electron micrography, ${ }^{11,12}$ would also relate to the polymer-clay interaction. Although $\alpha$-type crystalline is favored in pure nylon 6 , the considerable formation of $\gamma$-type crystalline of nylon 6 has been observed in NCH by wide angle X-ray diffraction (WAXD) and transmission electron micrography. ${ }^{13}$ The crystalline phase of polyamide in $\mathrm{NCH}$ has been also confirmed by Fourier transform infrared spectrometry (FT IR) measurements. ${ }^{14}$ The molecular level interaction between polymer chain and clay mineral in $\mathrm{NCH}$, however, has not been fully clarified.

On the other hand, the thermal properties such as glass-transition temperature $\left(T_{\mathrm{g}}\right)$ and melting point $\left(T_{\mathrm{m}}\right)$ of polymer blend and/or hybrid systems, in which much dense interactions between the constituent polymers exist in molecular level, are often quite different from those estimated from the behaviors of the corresponding pure polymers. Thus thermal analysis techniques such as differential scanning calorimetry (DSC) have been frequently used for evaluating the miscibility of polymer blend systems. In addition, thermal decomposition of a polymer blend also often

${ }^{\dagger}$ To whom correspondence should be addressed (Tel: +81-52-735-7911, Fax: +81-52-735-5368, E-mail: ohtani.hajime@nitech.ac.jp). 
exhibits unique profiles, which has been frequently monitored by thermogravimetry (TG). Recently, thermal degradation behavior of nylon 6/clay nanocomposites was also discussed using TG coupled with FT IR. ${ }^{15,16}$

Meanwhile we have demonstrated that the temperature programmed pyrolysis (TPPy) technique, that is a modern evolved gas analysis (EGA) equipped with highly specific and sensitive detectors such as a mass spectrometer (MS) and an atomic emission detector (AED), was successfully applied to the characterization of chitin-based polymer hybrids. ${ }^{17,18}$ In these studies, the observed evolution profiles of the characteristic products were interpreted in terms of the intermolecular interaction in the blend systems.

In this paper, the TPPy techniques were applied to the characterization of the $\mathrm{NCH}$ samples to investigate the interactions between nylon 6 molecules and clay surface in $\mathrm{NCH}$. The pyrolysis product of the nylon 6 matrix in the $\mathrm{NCH}$ samples was on-line monitored as a function of temperature by a mass spectrometer (MS) directly connected with the pyrolysis device. In addition, the individual products formed during the TPPy process were characterized in detail by using TPPy-gas chromatography (GC) technique. By comparing the observed pyrolysis behavior of $\mathrm{NCH}$ with that of conventional nylon 6-clay composites (NCC), in which multi-layer structure of clay minerals was maintained in the nylon 6 matrix, the interaction between nylon 6 and clay surface in the $\mathrm{NCH}$ samples were discussed.

\section{EXPERIMENTAL}

\section{Samples}

Table I summarizes the NCH and NCC samples used in this study. $\varepsilon$-Caprolactam purchased from Wako Co. and montmorillonite "Kunipia F" supplied by Kunimine Ind. Co. were used as the raw materials for the NCH samples. The NCH samples were prepared according to the previous paper. ${ }^{6}$ At first, so-

Table I. NCH and NCC samples

\begin{tabular}{ccc}
\hline Sample codes & $\begin{array}{c}\text { Clay contents } \\
(\text { wt } \%)\end{array}$ & $\begin{array}{c}\text { Number average molecular } \\
\text { weight }\left(M_{\mathrm{n}}\right) \text { of Nylon 6 }\end{array}$ \\
\hline NCH-A & 1.7 & 15000 \\
NCH-B & 4.5 & 9000 \\
NCH-C & 8.4 & 5500 \\
NCH-D & 12.4 & 4000 \\
\hline NCC-A & 1.3 & 15000 \\
NCC-B & 3.8 & 15000 \\
NCC-C & 7.4 & 15000 \\
NCC-D & 10.8 & 15000 \\
\hline Control Nylon 6 & & 15000 \\
\hline
\end{tabular}

dium ions in the montmorillonite were exchanged for ammonium ions of 12-aminododecanoic acid. Then, various contents of the organophilic montmorillonite (up to $c a$. $15 \mathrm{wt} \%$ ) were mixed with $\varepsilon$-caprolactam monomer. The polymerizations were carried out at $250^{\circ} \mathrm{C}$ for $6 \mathrm{~h}$. It was confirmed by the transmission electron micrograph observation that clay silicate monolayers were dispersed in the nylon matrix in the prepared NCH samples. ${ }^{19}$ The resulting products were mechanically crashed and washed with water at $80^{\circ} \mathrm{C}$ for $1 \mathrm{~h}$ to remove residual monomer and oligomers. To compare with $\mathrm{NCH}$, the NCC samples were prepared by blending nylon 6 (UBE Ind. Co., $M_{\mathrm{n}}=$ $15,000)$ and the montmorillonite in a twin screw extruder (Japan Steal Works LTD. TEX30 $\alpha-45.5 B W$, $\mathrm{L} / \mathrm{D}=45.5$ ). The final contents of montmorillonite in the NCH and NCC samples were listed in Table I along with the number average molecular weight $\left(M_{\mathrm{n}}\right)$ of the nylon 6 moiety. The clay contents were calculated from the residual weight after burning the samples. $M_{\mathrm{n}}$ of the nylon 6 moiety in $\mathrm{NCH}$ was determined by end group analysis of carboxylic acid through titration with a hot benzyl alcohol solution of $\mathrm{NaOH}$. All the samples were cryo-milled into fine powder by a freezer mill (Spex 6750) at liquid nitrogen temperature $\left(-196^{\circ} \mathrm{C}\right)$ prior to TPPy measurements.

\section{TPPy Measurements}

The TPPy-MS system used in this study is basically the same as that described in our previous papers. ${ }^{17,18,20}$ In this system, a temperature-programmable microfurnace pyrolyzer (Frontier Lab, PY-2010D) attached to a GC (Hewlett Packard, HP-5890) injector at $300^{\circ} \mathrm{C}$ was directly coupled with a quadrupole MS (JEOL, AM-II 150) via a deactivated stainless steel capillary (Frontier Lab, UADTM-5M, $0.25 \mathrm{~mm}$ i.d. $\times$ $5 \mathrm{~m}$ long). About $0.2 \mathrm{mg}$ of a sample was used for TPPy measurements, which should be small enough to achieve instantly thermodynamic equilibrium during programmed heating. A given sample placed in a platinum sample cup was heated in the pyrolyzer from 150 up to $600^{\circ} \mathrm{C}$ at a heating rate of $10^{\circ} \mathrm{C} / \mathrm{min}$ under helium atmosphere with a flow rate of $50 \mathrm{~mL} /$ min. A part of the flow $(1 \mathrm{~mL} / \mathrm{min})$ reduced by a GC splitter (50:1) was continuously introduced into MS through the transfer capillary. The transfer capillary was maintained at $300^{\circ} \mathrm{C}$ in the $\mathrm{GC}$ oven to prevent condensation of less volatile products in the capillary. For the MS measurement, ionization was carried out by electron impact (EI) at $70 \mathrm{eV}$, and an operating mass range was $10-500 \mathrm{amu}$ with a scan rate of $0.3 \mathrm{~s} / \mathrm{scan}$.

In order to identify and quantify the individual evolved products, TPPy-GC measurement was also 
(a)

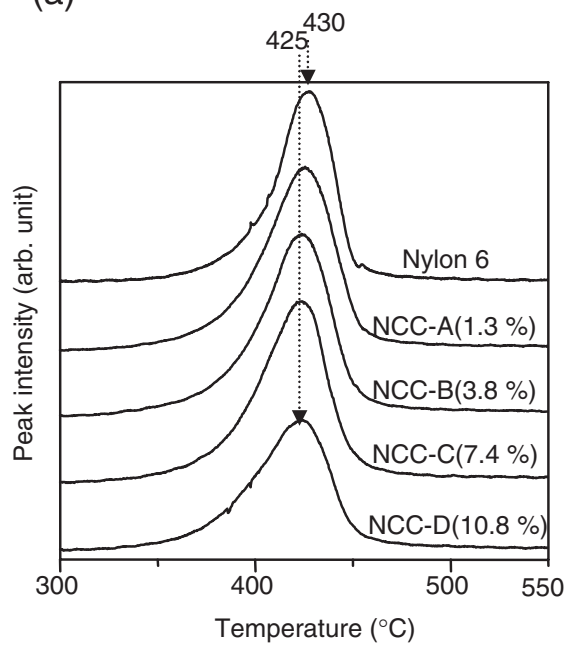

(b)

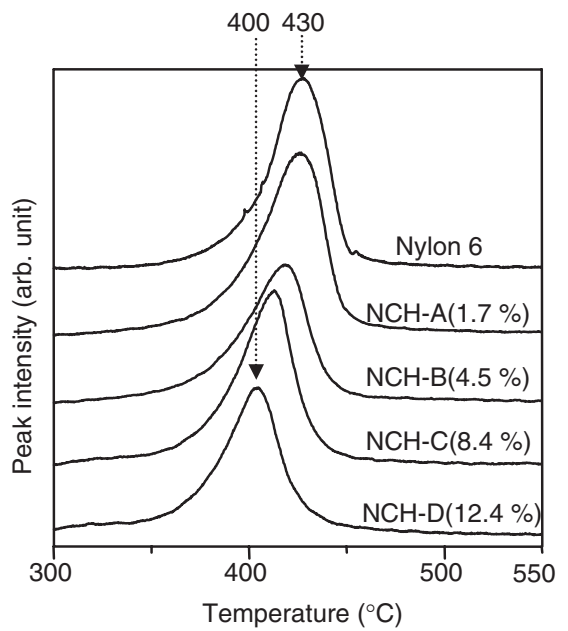

Figure 1. Evolution profiles of pyrolysis products from (a) NCC and (b) NCH samples observed by TPPy-MS in total ion current mode. Peak intensities are normalized by weight of nylon 6 matrix in the samples.

carried out. In this case, the capillary transfer line for the TPPy-MS system was replaced by a metal capillary separation column (Frontier Lab, Ultra Alloy ${ }^{+}-5$; $0.25 \mathrm{~mm}$ i.d. $\times 30 \mathrm{~m}$ long) coated with immobilized $5 \%$ diphenyl-95\% dimethylpolysiloxane $(0.25 \mu \mathrm{m}$ film). During the programmed heating periods from 150 up to $600^{\circ} \mathrm{C}$ for $45 \mathrm{~min}$, the thermal decomposition products were trapped at the entrance part of the GC column held at $-196^{\circ} \mathrm{C}$ using a microjet cryotrap (Frontier Lab, MJT-1030E). In addition to mass spectrometer, a flame ionization detector (FID) and FT IR (Bourne Scientific Infrared Chromatography) were also used for the detection of the separated products for quantification and complementary identification, respectively. In the TPPy-GC/FT IR measurement, HP $6890 \mathrm{GC}$ was used instead of HP 5890. After finishing the TPPy procedure, the column temperature was quickly raised to $50^{\circ} \mathrm{C}$ and then heated up to $300^{\circ} \mathrm{C}$ at a rate of $5{ }^{\circ} \mathrm{C} / \mathrm{min}$ and held for $10 \mathrm{~min}$. The other conditions were basically the same as those for the TPPy-MS measurement described above.

\section{RESULTS AND DISCUSSION}

\section{TPPy-MS Measurement}

Figure 1 shows the evolution profiles of the pyrolysis products from (a) NCC and (b) NCH samples with different clay contents together with control pure nylon 6 observed by TPPy-MS in a total ion current (TIC) mode. Here the peak intensities are normalized by the weight of nylon 6 matrix in the samples. The TIC curve of control nylon 6 shows apparently single-stage decomposition in the temperature range between $c a .350$ and $460^{\circ} \mathrm{C}$ with a peak top at around $430^{\circ} \mathrm{C}$. The evolution profiles of the NCC samples (Figure 1a) are almost equivalent to that of control

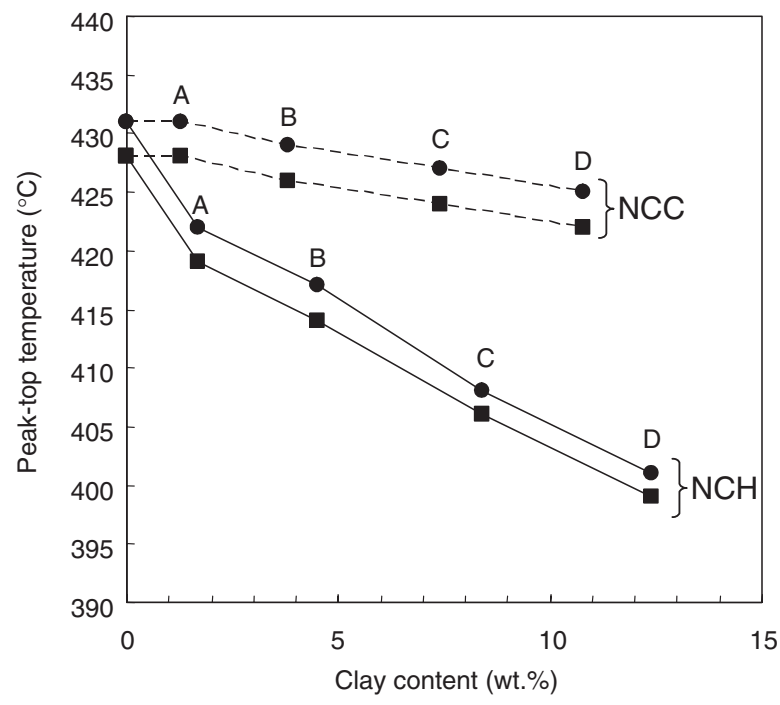

Figure 2. Relationship between clay content and peak-top temperatures observed by TPPy-MS in selected ion monitoring mode at $m / z, 96(\bullet)$ corresponding to fragment ions of nitrile compounds and $m / z 113$ (ם) to parent ion of $\varepsilon$-caprolactam for $\mathrm{NCH}$ (straight line) and NCC (dotted line) samples.

nylon 6; the change in the peak-top decomposition temperature is quite small $\left(\mathrm{ca} .5^{\circ} \mathrm{C}\right)$ even for the highest clay content (NCC-D). On the other hand, those of the $\mathrm{NCH}$ samples (Figure 1b) clearly shift to lower temperature region with the increase in the clay content. This result might be caused by the introduction of the clay monolayers dispersed in nylon 6 matrix for $\mathrm{NCH}$.

In order to study the thermal decomposition behavior of nylon 6 influenced by the clay in detail, the changes in the evolution temperature of some representative products of nylon 6 during TPPy were precisely examined using selected ion monitoring (SIM) 


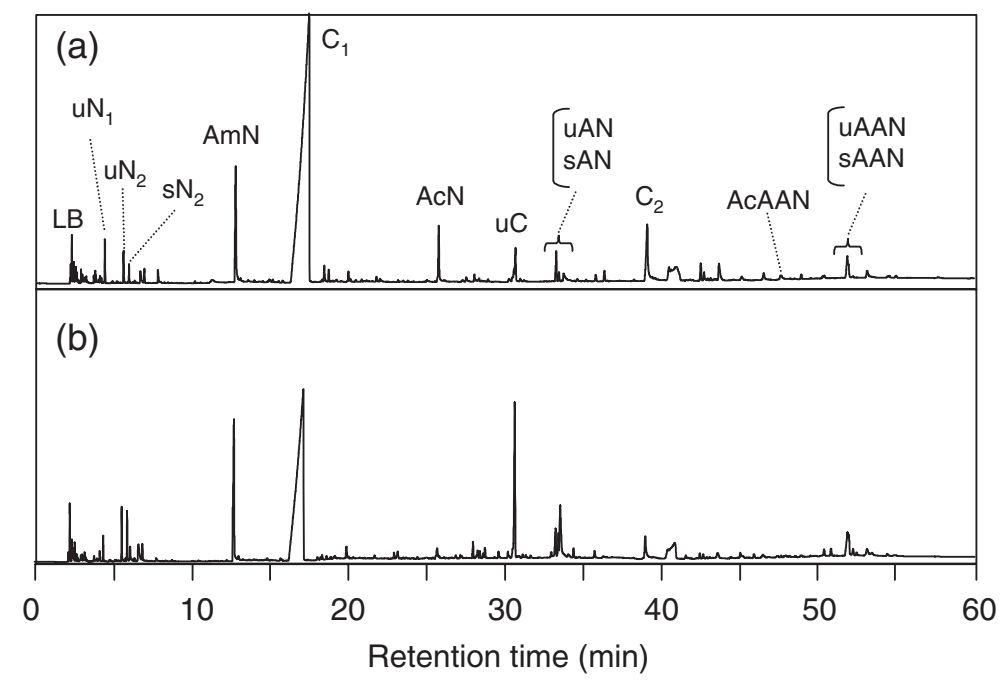

Figure 3. Pyrograms observed by TPPy-GC: (a) control pure nylon 6, (b) NCH-D (12.4 wt \% clay). Peak assignments are listed in Table II and peak intensities are normalized by weight of nylon 6 matrix in the samples.

mode. Figure 2 shows the relationship between the peak-top temperatures of the SIM thermograms at $m / z 113$ and 96 observed for the NCH and NCC samples together with those for control nylon 6 . Here, the ion observed at $\mathrm{m} / z, 113$ corresponds to molecular ion of $\varepsilon$-caprolactam, whereas that at $\mathrm{m} / z 96$ to the characteristic fragment of nitrile compounds, respectively, both of which are known to be the major pyrolysis products of nylon $6 .{ }^{21-23}$ Although the average molecular weight of the nylon matrix in NCH-A is comparable to those of NCC-A and control nylon $6\left(M_{\mathrm{n}}=\right.$ 15000), the peak-top decomposition temperatures for NCH-A are significantly lower than those for NCCA and control nylon 6. Furthermore, as the clay content in the NCH samples increases up to $12.4 \mathrm{wt} \%$, the peak-top temperatures of both compounds gradually lowered from $c a .430^{\circ} \mathrm{C}$ to $c a .400^{\circ} \mathrm{C}$. In the case of NCC samples, however, the shift in the decomposition temperature are limited to only $5{ }^{\circ} \mathrm{C}$ even for the NCC sample with the higher clay content (up to $10.8 \mathrm{wt} \%$ ). This fact indicates that pyrolysis reactions of nylon 6 are considerably influenced by the molecular-level interaction between nylon 6 matrix and clay surface rather than molecular weight of nylon 6 matrix.

\section{TPPy-GC Measurement}

Figure 3 shows TPPy gas chromatograms of (a) control nylon 6 and (b) NCH-D (12.4 wt \% clay). The thermal decomposition products of nylon 6 matrix during TPPy were identified by TPPy-GC/ MS and TPPy-GC/FT IR measurements. The assigned products are listed in Table II. On the both pyrograms, a strong peak of $\varepsilon$-caprolactam $\left(\mathbf{C}_{\mathbf{1}}\right)$ is commonly observed together with $\varepsilon$-caprolactam dimer $\left(\mathbf{C}_{2}\right)$, various nitrile compounds (peak symbols containing $\mathbf{N}$ ),
Table II. Pyrolysis products of nylon 6 identified by TPPy-GC/MS

\begin{tabular}{|c|c|}
\hline Peak $^{\mathrm{a}}$ & Products \\
\hline LB & low boiling point products such as propylene \\
\hline $\mathrm{uN}_{1}$ & $\mathrm{CH}_{2}=\mathrm{CH}\left(\mathrm{CH}_{2}\right)_{2}-\mathrm{CN}$ \\
\hline $\mathrm{uN}_{2}$ & $\mathrm{CH}_{2}=\mathrm{CH}\left(\mathrm{CH}_{2}\right)_{3}-\mathrm{CN}$ \\
\hline $\mathrm{sN}_{2}$ & $\mathrm{CH}_{3}\left(\mathrm{CH}_{2}\right)_{4}-\mathrm{CN}$ \\
\hline $\mathrm{AmN}$ & $\mathrm{NC}-\left(\mathrm{CH}_{2}\right)_{5}-\mathrm{NH}_{2}$ \\
\hline $\mathrm{C}_{1}$ & \\
\hline $\mathrm{AcN}$ & $\mathrm{CH}_{3}-\mathrm{CONH}-\left(\mathrm{CH}_{2}\right)_{5}-\mathrm{CN}$ \\
\hline $\mathrm{uC}$ & $-\mathrm{CH}=\mathrm{CH}_{2}$ \\
\hline uAN & $\mathrm{CH}_{2}=\mathrm{CH}\left(\mathrm{CH}_{2}\right)_{3}-\mathrm{CONH}-\left(\mathrm{CH}_{2}\right)_{5}-\mathrm{CN}$ \\
\hline sAN & $\mathrm{CH}_{3}-\left(\mathrm{CH}_{2}\right)_{4}-\mathrm{CONH}-\left(\mathrm{CH}_{2}\right)_{5}-\mathrm{CN}$ \\
\hline $\mathrm{C}_{2}$ & \\
\hline AcAAN & $\mathrm{CH}_{3}-\mathrm{CONH}-\left(\mathrm{CH}_{2}\right)_{5}-\mathrm{CONH}-\left(\mathrm{CH}_{2}\right)_{5}-\mathrm{CN}$ \\
\hline uAAN & $\mathrm{CH}_{2}=\mathrm{CH}\left(\mathrm{CH}_{2}\right)_{3}-\mathrm{CONH}-\left(\mathrm{CH}_{2}\right)_{5}-\mathrm{CONH}-\left(\mathrm{CH}_{2}\right)_{5}-\mathrm{CN}$ \\
\hline sAAN & $\mathrm{CH}_{3}\left(\mathrm{CH}_{2}\right)_{4}-\mathrm{CONH}-\left(\mathrm{CH}_{2}\right)_{5}-\mathrm{CONH}-\left(\mathrm{CH}_{2}\right)_{5}-\mathrm{CN}$ \\
\hline
\end{tabular}

${ }^{a}$ Abbreviations are the same as those in Figure 3. N: nitrile terminal, Am: amine terminal, A: amide linkage, Ac: $N$-acetyl terminal, C: caprolactam monomer, u: unsaturated hydrocarbon terminal, s: saturated hydrocarbon terminal.

and a hybrid compound of $\varepsilon$-caprolactam $(\mathbf{C})$ and an unsaturated (u) hydrocarbon terminal (uC). The fundamental pyrolysis mechanisms of nylon 6 have been already reported by using flash Py-GC at $500{ }^{\circ} \mathrm{C}^{22}$ and direct Py-MS in vacuum ion source. ${ }^{24}$ However, the 


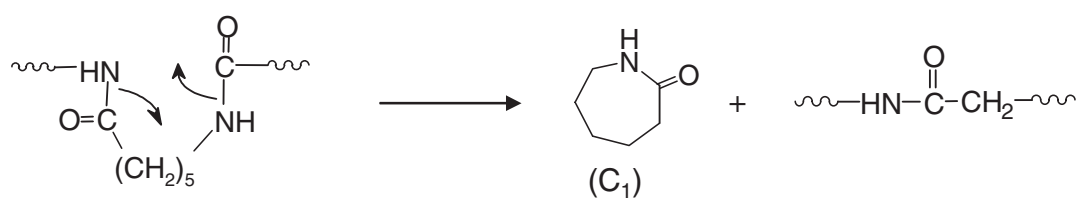

Scheme 1.

(a) $\beta-\mathrm{CH}$ hydrogen transfer

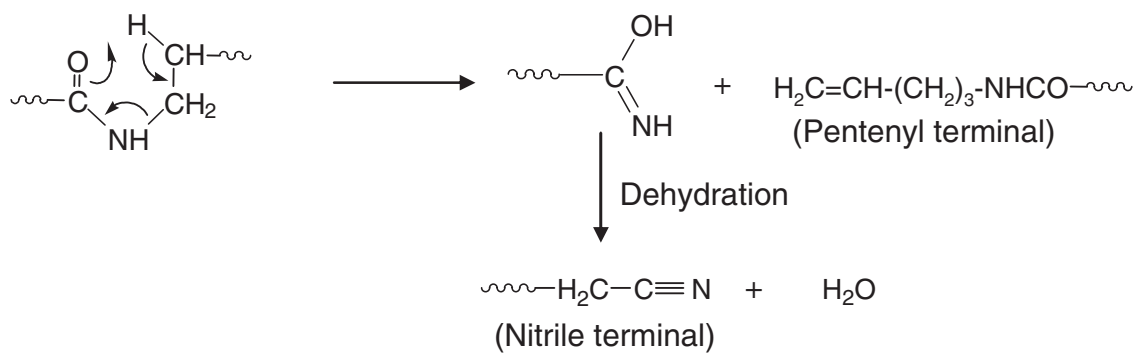

(b) $\gamma-\mathrm{CH}$ hydrogen transfer

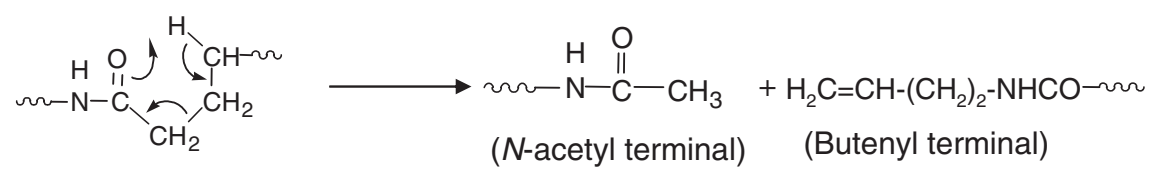

Scheme 2.

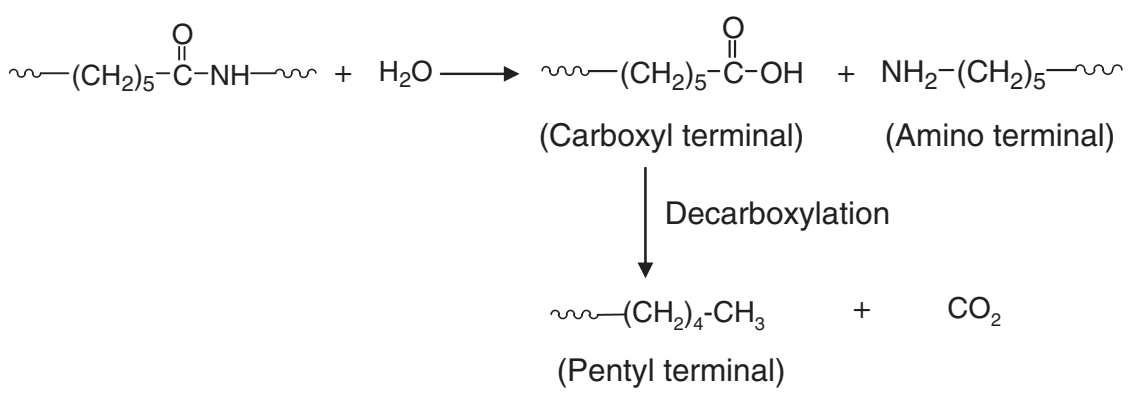

Scheme 3.

pyrolysis products of nylon 6 observed by TPPy-GC were somewhat different from those by flash pyrolysis in the previous reports. For example, the relative yields of 5-aminocapronitrile ( $\mathbf{A m N}), 5$-acetoaminocapronitrile $(\mathbf{A c N})$ and the hybrid compound $(\mathbf{u C})$ were much more enhanced in the case of TPPy. This difference in the pyrolysis behavior should be mostly attributed to the slower heating rate for TPPy. ${ }^{25}$ Scheme 1 shows the possible formation mechanism of $\varepsilon$-caprolactam $\left(\mathbf{C}_{\mathbf{1}}\right)$, through intramolecular amideexchange reaction. ${ }^{22,25}$ The cyclic dimer $\left(\mathbf{C}_{2}\right)$ should be produced in a similar manner. Another major pyrolysis pathway of polyamide is generally known to be cis-elimination reaction to cleavage polyamide chain. ${ }^{21,22}$ As shown in Scheme 2, two types of the transition states are possible for nylon 6; one is caused by $\beta$-CH proton transfer to form a pair of intermedi- ates having amide and hexenyl termini (Scheme 2a) and the other is by $\gamma-\mathrm{CH}$ proton transfer to a pair of $\mathrm{N}$-acetyl and butenyl termini (Scheme 2b). The amide terminus would be further dehydrated into a nitrile group under the given TPPy conditions. In addition, hydrolysis of the amide linkage to generate a pair of carboxyl and amino termini would be also possible as shown in Scheme 3. The intermediate having a carboxyl terminal could be further decomposed by decarboxylation to form a saturated hydrocarbon (pentyl) terminal. The formations of most of the observed products can be explained by either combination of the chain cleavages in Schemes 2 and 3. Moreover, as shown in Scheme 4, the hybrid compound of $\varepsilon$-caprolactam and a pentenyl terminal $(\mathbf{u C})$ might be produced by the intramolecular cyclization of a carboxyl terminal moiety formed by hydrolysis (Scheme 3 ). 


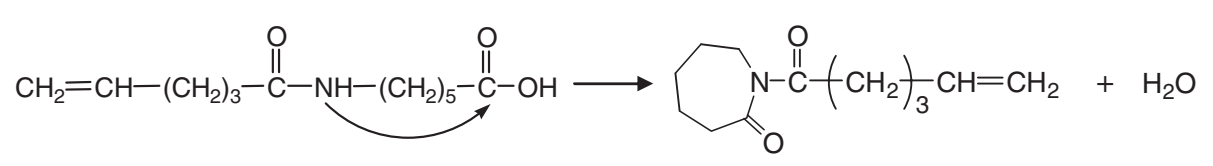

(uC)

Scheme 4 .

(a)

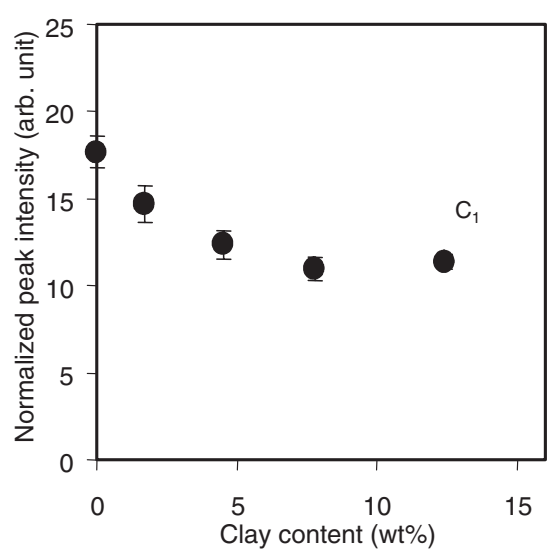

(b)

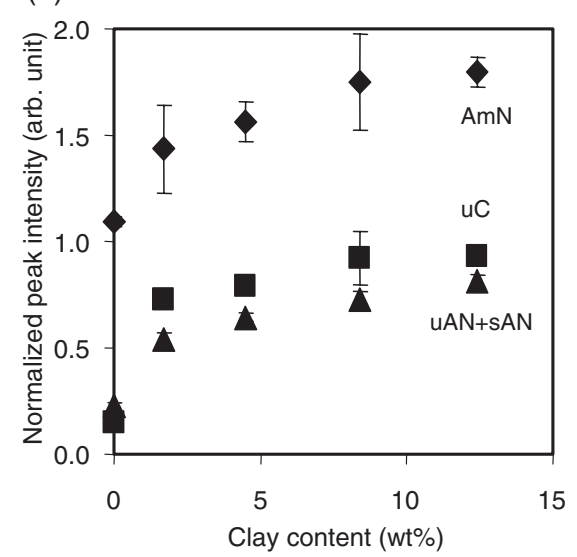

Figure 4. Changes in the yield of pyrolysis products of nylon 6 from $\mathrm{NCH}$ samples with clay content: (a) $\varepsilon$-caprolactam $\left(\mathrm{C}_{1}\right)$, (b) nitrile $(\mathrm{AmN}, \mathrm{uAN}+\mathrm{sAN})$ and hybrid $(\mathrm{uC})$ compounds.

Here, it is interesting to note that relative yields of several products are considerably different between the chromatograms of $\mathrm{NCH}$ and control pure nylon 6 as shown in Figure 3. The peak intensities of $\varepsilon$-caprolactam monomer $\left(\mathbf{C}_{\mathbf{1}}\right)$ and dimer $\left(\mathbf{C}_{\mathbf{2}}\right)$ and the products having $N$-acetyl group (AcN and AcAAN) from the $\mathrm{NCH}$ sample are obviously weaker than those from control nylon 6 . On the other hand, the peak intensities of the nitrile compounds except for $\mathbf{A c N}$ and AcAAN and hybrid compound (uC) are significantly stronger for $\mathrm{NCH}$.

Figure 4 shows the relationship between the clay content and the peak intensities of $\varepsilon$-caprolactam $\left(\mathbf{C}_{1}\right)$, some nitrile compounds without $N$-acetyl terminal $(\mathbf{A m N}, \mathbf{u A N}+\mathbf{S A N})$, and the hybrid compound (uC) observed in TPPy gas chromatograms of control nylon 6 and the NCH samples. The yield of $\varepsilon$-caprolactam gradually decreases with increase in the clay content and the decrement for NCH-D is $\mathrm{ca} .35 \%$ in comparison with the case of control nylon 6 (Figure 4a), while that of the nitrile and hybrid compounds considerably increase (Figure 4b). The decreased yields of $\varepsilon$-caprolactam during TPPy with increase in the clay content were also reported in a recent work about thermal decomposition of nylon 6-clay nanocomposites using TG/FT IR followed by GC-MS measurements of the evolved products. ${ }^{16}$ These observations are consistent with those observed by TPPy-MS measurements shown in Figure 2. The obtained results indicate that changes of the observed peak intensities with the clay content in the $\mathrm{NCH}$ samples would reflect the difference in the segmental interactions between nylon 6 molecule and clay surface.

\section{Possible Interaction between Nylon 6 and Clay Sur- face in $\mathrm{NCH}$}

The prominent influences of clay on the pyrolysis of nylon 6 matrix observed for the $\mathrm{NCH}$ samples can be summarized as follows: (1) lowering of pyrolysis temperature, (2) enhancement of the formation of the nitrile compounds, and (3) suppression of the formation of $\varepsilon$-caprolactam and $N$-acetyl products.

The lowering of pyrolysis temperature of nylon 6 matrix in the NCH samples suggests that clay surface act as catalyst for the pyrolysis of nylon 6 matrix. In the NCH samples, the surface area of clay interacting with nylon 6 molecules would be proportional to the clay content, because the clay monolayers are highly dispersed in the nylon 6 matrix. ${ }^{19}$ Therefore, the pyrolysis temperature is substantially decreased with the increase in the clay content. On the other hand, in the NCC samples, the effective surface area of the clay is limited even for the higher clay content since the silicate layers are condensed in the nylon 6 matrix. Hence, the pyrolysis temperature of nylon 6 matrix in the NCC samples is hardly changed.

The suppression of the formation of $\varepsilon$-caprolactam from the $\mathrm{NCH}$ samples and enhancement of that of various nitrile and hybrid compounds as shown in Figure 4 would also suggest that catalytic effect of 


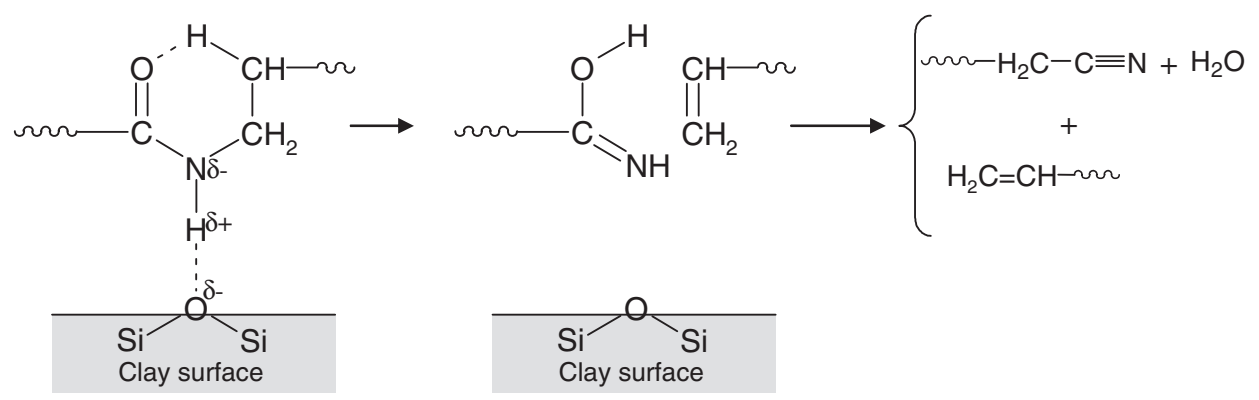

Scheme 5.

clay surface accelerating cis-elimination reaction rather than intramolecular amide exchange. As shown in Scheme 2, two types of cis-elimination reactions are possible, i.e., $\beta$ - and $\gamma$-CH proton transfer. The suppression of the formation of $\mathrm{N}$-acetyl compounds such as AcN and AcAAN suggests that the catalytic effect on the clay surface promotes predominantly the $\beta$ $\mathrm{CH}$ proton transfer type cis-elimination reaction to form nitrile terminal. Therefore, the possible interaction catalyzing the cis-elimination reaction can be proposed as shown in Scheme 5. In this mechanism, the interaction between positively charged $\mathrm{NH}$ proton of nylon 6 molecules and negatively charged clay surface would stabilize the six-membered transition state and promote the cis-elimination reaction with $\beta$-CH transfer. As a result, the amounts of various nitrile compounds formed from nylon 6 matrix would increase in the presence of clay. At the same time, the water produced by dehydration of amide terminus into nitrile would enhance hydrolysis of amide linkages to form a pair of carboxyl and amino terminals (Scheme 3). Since the carboxyl terminals could be converted to pentyl ones and cyclic moieties in the hybrid compound, the increasing formation of amino compound $(\mathbf{A m N})$, pentyl compounds (sN2, sAN, and $\mathbf{S A A N})$ and hybrid compound $(\mathbf{u C})$ with increase in the clay content (Figure $4 \mathrm{~b}$ ) also supports the proposed interaction between nylon 6 and the clay surface.

Acknowledgment. This work was supported in part by Grant-in-Aid for Scientific Research (B) (16350081) of Japan Society for the Promotion of Science, and Grant-in-Aid for Waste Management (K1734) of the Ministry of the Environment, Japan.

\section{REFERENCES}

1. P. C. LeBaron, Z. Wang, and J. Pinnavaia, Appl. Clay Sci., 15, 11 (1999).

2. H. R. Fischer, L. H. Gielgens, and T. P. M. Koster, Acta Polym., 50, 122 (1999).

3. M. Kato and A. Usuki, in "Polymer-Clay nanocomposites,"
J. Pinnavaia and G. W. Beall, Ed., Wiley, 2000, p 97.

4. M. Biswas and S. S. Ray, Adv. Polym. Sci., 155, 167 (2001).

5. S. S. Ray and M. Okamoto, Prog. Polym. Sci., 28, 1539 (2003).

6. A. Usuki, N. Hasegawa, M. Kato, and S. Kobayashi, $A d v$. Polym. Sci., 179, 135 (2005).

7. A. Usuki, Y. Kojima, M. Kawasumi, A. Okada, Y. Fukushima, T. Kurauchi, and O. Kamigaito, J. Mater. Res., 8, 1179 (1993).

8. A. Okada, A. Usuki, T. Kurauchi, and O. Kamigaito, ACS Symp. Ser., 585, 55 (1995).

9. A. Usuki, A. Koiwai, Y. Kojima, M. Kawasumi, A. Okada, T. Kurauchi, and O. Kamigaito, J. Appl. Polym. Sci., 55, 119 (1995).

10. A. Okada and A. Usuki, Mater. Sci. Eng., C, 3, 109 (1995).

11. T. D. Fornes, P. J. Yoon, H. Keskkula, and D. R. Paul, Polymer, 42, 9929 (2001).

12. T. M. Wu and J. Y. Wu, J. Macromol. Sci., Phys., B41, 17 (2002).

13. Y. Kojima, A. Usuki, M. Kawasumi, A. Okada, T. Kurauchi, O. Kamigaito, and K. Kaji, J. Polym. Sci., Part B: Polym. Phys., 32, 625 (1994).

14. Q. Wu, X. Liu, and L. A. Berglund, Polymer, 43, 2445 (2002).

15. K. P. Pramoda, T. Liu, Z. Liu, C. He, and H. J. Sue, Polym. Degrad. Stab., 81, 47 (2003).

16. B. N. Jang and C. A. Wilkie, Polymer, 46, 3264 (2005).

17. H. Sato, S. Tsuge, H. Ohtani, K. Aoi, A. Takasu, and M. Okada, Macromolecules, 30, 4030 (1997).

18. H. Sato, H. Ohtani, S. Tsuge, K. Aoi, A. Takasu, and M. Okada, Macromolecules, 33, 357 (2000).

19. A. Usuki, N. Hasegawa, H. Kadoura, and T. Okamoto, Nano Lett., 1, 271 (2001).

20. H. Sato, K. Kondo, S. Tsuge, H. Ohtani, and N. Sato, Polym. Degrad. Stab., 62, 41 (1998).

21. I. Luederwald and F. Merz, Angew. Makromol. Chem., 74, 165 (1978).

22. H. Ohtani, T. Nagaya, Y. Sugimura, and S. Tsuge, J. Anal. Appl. Pyrolysis, 4, 117 (1982).

23. S. V. Levchik, E. D. Weil, and M. Lewin, Polym. Int., 48, 532 (1999).

24. A. Ballistreri, D. Garozzo, M. Giuffrida, G. Impallomeni, and G. Montaudo, Polym. Degrad. Stab., 23, 25 (1989).

25. R. S. Lehrle, I. W. Parsons, and M. Rollinson, Polym. Degrad. Stab., 67, 21 (2000). 